\title{
PENGARUH 4S's (Swaddling, Side, Shushing, Swinging) TERHADAP HEART RATE NEONATUS PASKA PENGAMBILAN DARAH VENA DI RUANG EDELWEIS RSUD NGUDI WALUYO WLINGI (The Effectiveness Of 4s's (Swaddling, Side, Shushing, Swinging) To The Neonates Heart Rate Post Venous Blood Sampling In Edelweis Ward RSUD Ngudi Waluyo Wlingi)
}

\author{
Husna Rahmawati, Erni Setiyorini \\ Pendidikan Ners, STIKes Patria Husada Blitar \\ email: nerserni@gmail.com
}

\begin{abstract}
Neonates experience changes in all the systems one of the most dramatic changes is the cardiovascular system. Neonates born in hospitals Wlingi all venous blood should be taken where the effect of this action is definitely cause discomfort which can affect the heart rate of neonates. Techniques that can improve the comfort of one of them with techniques 4S's (swaddling, side, shushing, swinging) The purpose of this study was to determine the effect on heart rate 4S's post neonatal venous blood sampling.This research design using posttest only control group. The research was conducted at room Edelweiss Ngudi Waluyo Hospital Wlingi for 1 month (5-29 November 2014). Subjects were neonates who meet the inclusion criteria. The total sample of 34 neonates in the two groups of 17 treatment group and 17 control group. Sampling using accidental sampling technique. The collection of data through observation in the treatment group and the control group. Data were analyzed by T-test.The results showed heart rate is lower in the treatment group compare the control group. The results of the statistical test showed P-valiu $=0.001$ which means that there is an influence on heart rate 4S's post neonatal venous blood sampling.It is hoped with this study 4S's technique can be applied by health workers and parents to provide comfort in neonates.
\end{abstract}

Keywords : Neonates, heart rate, 4S's, venous blood sampling.

\begin{abstract}
Abstrak : Neonatus mengalami perubahan pada semua sistem salah satu perubahan paling dramatis adalah sistem kardiovaskular. Neonatus yang lahir di rumah sakit Wlingi semua darah vena harus diambil, salah satu efek dari tindakan ini pastinya menimbulkan ketidaknyamanan yang dapat mempengaruhi denyut jantung neonatus. Teknik yang dapat meningkatkan kenyamanan salah satunya dengan teknik 4 S's (swaddling, side, shushing, swinging) Tujuan dari penelitian ini adalah untuk mengetahui efek pengambilan sampel darah vena neonatal jantung berdarah 4S. Desain penelitian ini menggunakan kelompok kontrol post test saja. Penelitian dilaksanakan di ruang Edelweiss Rumah Sakit Ngudi Waluyo Wlingi selama 1 bulan (5-29 November 2014). Subyek adalah neonatus yang memenuhi kriteria inklusi. Sampel total 34 neonatus pada kedua kelompok perlakuan 17 kelompok perlakuan dan 17 kelompok kontrol. Pengambilan sampel menggunakan teknik accidental sampling. Pengumpulan data melalui observasi pada kelompok perlakuan dan kelompok kontrol. Data dianalisis dengan uji T. Hasil penelitian menunjukkan bahwa denyut jantung lebih rendah pada kelompok perlakuan dibandingkan kelompok kontrol. Hasil uji statistik menunjukkan P-valiu $=0,001$ yang berarti bahwa ada pengaruh pada pengambilan sampel darah vena darah vena denyut jantung 4 S. Diharapkan dengan teknik penelitian ini $4 \mathrm{~s}$ dapat diterapkan oleh petugas kesehatan dan orang tua untuk memberikan kenyamanan pada neonatus.
\end{abstract}

Kata Kunci: Neonatus, detak jantung, pengambilan sampel darah vena, 4s. 
Neonatus adalah bayi dari lahir sampai usia 4 minggu, lahir biasanya dengan usia gestasi 38-42 minggu (Wong,2003). Neonatus harus memenuhi sejumlah tugas perkembangan untuk memperoleh dan mempertahankan ekstensi fisik secara terpisah dari ibunya. Neonatus harus beradaptasi dengan perubahan lingkungan dari intra uterin ke ekstra uteri. Neonatus adalah mulai dari lahir sampai usia atau bulan periode neonatal. Neonatus adalah bulan pertama selama periode neonatal bayi mengalami pertumbuhan dan perubahan yang amat menabjubkan (Hamilton,1995).

Perubahan yang di alami bayi terjadi pada semua sistem salah satunya sistem kardiovaskuler. Perubahan secara fisiologis pada sistem kardiovaskuler yaitu penutupan foramen ovale pada atrium jantung, penutupan duktus anteriosus antara arteri paru dan aorta dan penutupan duktus venosus, perubahan ini terjadi akibat adanya tekanan pada seluruh sistem pembuluh darah (Nelson, 1999).

Ketidaknyamanan yang di alami pada neonatus yang di rawat di RSUD Ngudi Waluyo Wlingi salah satunya disebabkan oleh adanya tindakan pengambilan darah vena merupakan prosedur yang menimbulkan kecemasan dan ketakutan serta rasa tidak nyaman bagi bayi akibat nyeri yang dirasakan saat prosedur tersebut di laksanakan (Zeltzer \& Brown 2007).

Dari beberapa efek dari tindakan pengambilan darah vena adalah ketidaknyamanan yang ditangani ataupun yang tidak di tangani secara fisiologis dan bio kimia menimbulkan gejala sisa salah satunya peningkatan denyut jantung dan tekanan darah (Pokela,1994; dalam Wong, 2006) Di satu sisi sistem kardiovaskuler pada neonatus masih dalam proses adaptasi sistem yang sangat dramatis sehingga bila proses ini tidak bisa maksimal oleh karena adanya gangguan dari fungsi jantung yang di akibatkan oleh salah satu faktor ketidaknyamanan efek dari pengambilan sampel darah yang berkepanjangan bila tidak di atasi segera tentunya akan menimbulkan efek yang kurang baik untuk jantung.

Sedangkan manajemen nyeri paska pengambilan darah yang di lakukan di ruang Edelweis RSUD Ngudi Waluyo Wlingi masih konvensional yakni swaddling (pembedongan) saja, dimana cara ini masih kurang efektif untuk mengurangi ketidaknyamanan/nyeri yang di alami oleh neonatus. Beberapa riset menunjukkan bahwa kegagalan dalam mengatasi nyeri pada neonatus akan menyebabkan perubahan permanen pada proses di otak dan perilaku maladaptif selanjutnya (Anand, 2000). Oleh sebab itu perawat perlu mempertimbangkan bagaimana meminimalkan ketidaknyamanan dan nyeri yang dirasakan oleh bayi (Lissaue dan Fanaroffr, 2011).

Bayi mengkomunikasikan ketidaknyamanannya kepada kita dengan cara menangis (BabyCentre Medical Advisory Board, 2012).

Penemuan konsep baru bahwa neonatus sampai dengan usia 3 bulan tidak sepenuhnya siap di dunia, sehingga neonatus yang menangis dapat dikondisikan seperti di dalam rahim ibu. Dr. Karp mengajarkan teknik untuk "mengkondisikan ulang seperti dalam kandungan" agar neonatus tenang dan nyaman, dengan metode 5S's yang meliputi swaddling (membedong bayi), side posisi miring ke kiri/perut, shushing sound, swinging (gerakan berayun), sucking (mengisap). Tehnik tersebut dilakukan karena selama tiga bulan pertama setelah kelahirannya, bayi merindukan sensasi-sensasi nyaman yang mereka alami selama berada dalam rahim. Berdasarkan hasil penelitian yang dilakukan oleh Dr.Harrington (2010) menyatakan bahwa sebagian besar neonatus yang mendapatkan intervensi fisik $5 \mathrm{~S}$ 's berhenti menangis dengan 45 detik, sedangkan yang menerima larutan gula masih menangis 2 menit setelah prosedur invasif vaksinasi (Gupta, 2012). Pada bayi yang diambil darahnya membutuhkan pelayanaan untuk memenuhi kenyamanannya (health care needs). Oleh sebab itu peneliti ingin mengaplikasikan metode 4S's untuk menenangkan bayi setelah dilakukan prosedur pengambilan darah vena, dengan harapan ketidaknyamanan yang dirasakan neonatus berkurang/ hilang dan neonatus dapat merasa tenang dan nyaman, sehingga efek dari ketidaknyamanan yang meningkatkan kerja jantung tidak memberikan dampak yang buruk pada jantung.

Intervensi yang di lakukan pada penelitian ini adalah 4S's dengan pertimbangan di RSUD Ngudi Waluyo Wlingi untuk tehnik sucking belum bisa diaplikasikan karena dikawatirkan media yang di gunakan yakni niple dot menjadi media masuknya kuman melalui mulut lalu ke saluran pencernaan neonatus yang dapat menimbulkan masalah pada gastro instestinal neonatus dan justru dengan pemberian niple dot ini dapat menimbulkan binggung puting susu ibu pada neonatus dan bertentangan dengan program RS bahwa neonatus harus di beri ASI tidak boleh susu formula. 
Berdasarkan uraian diatas, maka peneliti ingin mengetahui pengaruh teknik $4 \mathrm{~S}$ 's terhadap heart rate neonatus, sehingga petugas kesehatan dapat memberikan intervensi segera terhadap ketidaknyamanan neonatus paska pengambilan darah vena.

Tujuan penelitian ini adalah mengetahui pengaruh 4S's terhadap heart rate neonatus paska pengambilan darah vena di Ruang Edelweis RSUD Ngudi Waluyo Wlingi tahun 2014. Tujuan khususnya adalah 1) Mengidentifikasi heart rate neonatus pasca pengambilan darah vena setelah diberikan tehnik 4S's di Ruang Edelweis Wlingi tahun 2014. 2) Mengidentifikasi heart rate neonatus pasca pengambilan darah vena setelah diberikan teknik konvensional di Ruang Edelweis RSUD Ngudi Waluyo Wlingi tahun 2014. 3) Menganalisis pengaruh 4S's terhadap heart rate neonatus pasca pengambilan darah vena.

\section{BAHAN DAN METODE}

Desain penelitian ini adalah post test only control group design, dimana populasi dalam penelitian ini adalah neonatus yang dirawat di ruang Edelweis RSUD Ngudi Waluyo Wlingi dengan prosedur pengambilan darah pada bulan November 2014 sebanyak 183 neonatus. Sampel dalam penelitian ini adalah neonatus yang dirawat di ruang Edelweis RSUD Ngudi Waluyo Wlingi dengan prosedur pengambilan darah bulan November 2014 yang memenuhi kriteria inklusi penelitian sebanyak 34 neonatus. Sedangkan tehnik pengambilan sampel pada penelitian ini menggunakan tehnik accidental sampling. Adapun variabel dalam penelitian ini adalah (a) Variabel bebas adalah tehnik 4S's (swaddling, side, shushing, swinging). (b) Variabel tergantung adalah heart rate neonatus dan untuk mengetahui pengaruh variabel bebas dan variabel terikat dengan menggunakan analisis Uji normalitas data dengan menggunakan Shapiro-Wilk dan analisa data yang dilakukan dengan menggunakan T-test.

\section{HASIL PENELITIAN}

Hasil penelitian meliputi distribusi karakteristik neonatus kelompok perlakuan dan kontrol dan Heart Rate Neonatus kelompok perlakuan.

Tabel 1 Distribusi karakteristik Neonatus kelompok perlakuan dan kontrol di Ruang Edelweis RSUD. Ngudi Waluyo Wlingi tanggal 5 November- 29 November 2014

\begin{tabular}{|c|c|c|c|c|c|}
\hline \multirow{3}{*}{ No } & \multirow{3}{*}{ Karakteristik } & \multicolumn{4}{|c|}{ Kelompok } \\
\hline & & \multicolumn{2}{|c|}{ Perlakuan } & \multicolumn{2}{|c|}{ Kontrol } \\
\hline & & Frekuensi & Persentase $(\%)$ & Frekuensi & Persentase $(\%)$ \\
\hline \multirow[t]{3}{*}{1} & Jenis Kelamin & & & & \\
\hline & - Laki-laki & 7 & 41 & 9 & 53 \\
\hline & - Perempuan & 10 & 59 & 8 & 47 \\
\hline \multirow[t]{3}{*}{2} & Jenis Persalinan & & & & \\
\hline & - Normal & 6 & 35 & 4 & 24 \\
\hline & $-\mathrm{SC}$ & 11 & 65 & 13 & 76 \\
\hline \multirow[t]{5}{*}{3} & Pengambilan Darah & & & & \\
\hline & - Ke 1 & 6 & 35 & 5 & 29 \\
\hline & - Ke 2 & 8 & 47 & 8 & 47 \\
\hline & $-\mathrm{Ke} 3$ & 1 & 6 & 4 & 24 \\
\hline & - $\operatorname{Ke} 4$ & 2 & 12 & 0 & 0 \\
\hline \multirow[t]{4}{*}{4} & Usia neonatus & & & & \\
\hline & $-0-3$ hari & 9 & 53 & 14 & 82 \\
\hline & $-4-7$ hari & 6 & 35 & 1 & 6 \\
\hline & - $8-14$ hari & 2 & 12 & 2 & 12 \\
\hline
\end{tabular}


Tabel 2 Distribusi karakteristik Neonatus kelompok perlakuan dan kontrol diRuang Edelweis RSUD Ngudi Waluyo Wlingi tanggal 5 November-29 November 2014

\begin{tabular}{llcccccc}
\hline & & \multicolumn{9}{c}{ Kelompok } \\
\cline { 3 - 8 } No & \multirow{2}{*}{ Karakteristik } & Perlakuan & Kontrol \\
\cline { 3 - 8 } & & Min & Max & Mean & Min & Max & Mean \\
\hline 1 & BB (gram) & 2500 & 3950 & 3129,4 & 2500 & 3950 & 3014,7 \\
2 & $\mathrm{SaO} 2(\%)$ & 86 & 99 & 93,06 & 84 & 98 & 91,3 \\
\hline
\end{tabular}

Tabel 3 Heart Rate Neonatus kelompok perlakuan di Ruang Edelweis RSUD. Ngudi Waluyo Wlingi tanggal 5 November- 29 November 2014

\begin{tabular}{lccccc}
\hline Kelompok & N & Mean & Std. Deviation & Std. Error & Mean \\
\hline Heart Rate & perlakuan 4s's & 17 & 131,24 & 12,055 & 3,166 \\
\hline
\end{tabular}

Tabel 4 Heart Rate Neonatus kelompok kontrol di Ruang Edelweis RSUD. Ngudi Waluyo Wlingi tanggal 5 November- 29 November 2014

\begin{tabular}{lccccc}
\hline Kelompok & N & Mean & Std. Deviation & Std. Error & Mean \\
\hline Heart Rate & kontrol & 17 & 144,88 & 8,594 & 2,034 \\
\hline
\end{tabular}

Tabel 5 Heart rate neonatus kelompok perlakuan dan kelompok kontrol di Ruang Edelweis RSUD. Ngudi Waluyo Wlingi tanggal 5 November-29 November 2014

\begin{tabular}{lccccc}
\hline Kelompok & $\mathbf{n}$ & Mean & Min & Max & T-test \\
\hline Perlakuan & 17 & 131,23 & 111 & 156 & 0,001 \\
Kontrol & 17 & 144,8 & 132 & 162 & \\
\hline
\end{tabular}

Berdasarkan Tabel 1 dan 2 karakteristik responden berdasarkan jenis kelamin,jenis persalinan, pengambilan darah,usia neonatus, $\mathrm{BB}, \mathrm{SaO} 2$.

Tabel 3 kelompok perlakuan menunjukkan hasil heart rate rata-rata 131,24 standar deviasi 12,055 . Tabel 4 kelompok kontrol menunjukkan hasil heart rate rata-rata 144,88 standar deviasi 8,594 sedangkan Tabel 5 heart rate rata-rata kelompok perlakuan lebih rendah dibandingkan dengan heart rate rata-rata kelompok kontrol. Hasil uji statistik menunjukkan $p=0,001$ yang berarti ada pengaruh $4 \mathrm{~S}$ 's terhadap heart rate neonatus paska pengambilan darah vena.

\section{PEMBAHASAN}

\section{Heart Rate neonatus kelompok perlakuan}

Berdasarkan data karakteristik neonatus, sebagian besar neonatus pada kelompok perlakuan berjenis kelamin perempuan sebanyak 10 neonatus (59\%), jenis persalinan terbanyak SC yaitu 11 (65\%), dan prosedur pengambilan darah yang terbanyak adalah pengambilan darah yang ke 2 yaitu $8(47 \%)$, usia terbanyak $0-3$ hari yaitu 9 neonatus (53\%), $\mathrm{SaO} 2$ rata-rata 93,06\%. Berdasarkan penelitian Dyah Kanya Wati dkk dengan sampel 116 neonatus tidak didapatkan pengaruh jenis persalinan dengan kenyamanan neonatus. Pada kelompok perlakuan terdiri 25 neonatus yang dilakukan tindakan 4S,s (swaddling, side, shushing, swingging) paska pengambilan darah vena. Dari 25 neonatus hanya 17 neonatus di dapatkan berhenti menangis setelah di lakukan 4S's (swaddling, side, shushing, swingging), 4 neonatus berhenti menangis pada 2S's (swaddling, side), 4 neonatus berhenti pada 3S's (swaddling, side, shushing). Dari hasil observasi ini menunjukkan neonatus yang berhenti menangis setelah mendapatkan teknik 4S's (swaddling, side, shushing, swingging) lebih banyak dibandingkan dengan 8 neonatus yang berhenti menangis pada S's ke 2 dan 3. Dengan 4S's (swaddling, side, shushing, swingging) neonatus mendapatkan kenyamanan dan 
kesenangan sehingga respon tubuh akan melepaskan endorphin, enkefalin menuju reseptor diameter besar (A beta) sehinga gerbang tertutup dan impuls di hantar ke korteks serebral sehingga kenyamanan dan ketenangan meningkat akhirnya heart rate menurun/ normal. Heart rate kelompok perlakuan pada 17 neonatus menunjukkan hasil minimal $111 \mathrm{x} / \mathrm{mnt}$ maximal $132 \mathrm{x} / \mathrm{mnt}$ rata-rata $131,23 \mathrm{x} / \mathrm{mnt}$ menunjukkan dalam batas normal. Hasil ini mendukung pendapat Harvey Karp bahwa intervensi 4S's dapat menurunkan skala nyeri/ketidaknyamanan akibat dari tindakan invasif. Intervensi tindakan dengan 4S's merupakan salah satu dari penatalaksanaan nyeri/ ketidaknyamanan non farmakologik yaitu metode distraksi. Distraksi dapat menurunkan persepsi nyeri dengan menstimulasi sistem kontrol desenden sehingga stimulasi nyeri yang ditransmisikan ke otak lebih sedikit. Efektifitas teknik distraksi tergantung pada kemampuan individu dalam menerima dan membangkitkan stimuli sensoris selain dari rangsang nyeri yang diterima. Penurunan nyeri secara umum dapat optimal dengan melibatkan partisipasi aktif dari individu, keterlibatan modalitas sensoris yang digunakan dan minat individu terhadap stimuli (Smeltzer, 2002). Stimulasi dengan melibatkan beberapa indera seperti penglihatan, pendengaran, sentuhan lebih efektif dalam menurunkan ketidaknyamanan/nyeri dibandingkan dengan hanya melibatkan satu indera saja. Intervensi 4S's yaitu Swaddling, Side, Shushing, Swinging, melibatkan beberapa indera sehingga lebih efektif dalam menurunkan nyeri.

Sedangkan 8 neonatus yang berhenti menangis di 2 's dan 3S's, 4 neonatus di ambil darah ke 1 menunjukkan hasil heart rate minimal 79x/mnt maximal $158 \mathrm{x} / \mathrm{mnt}$ rata- rata $104,75 \mathrm{x} / \mathrm{mnt}, 4$ neonatus di ambil darah ke 2 menunjukkan heart rate minimal 139x/mnt maximal 165x/mnt rata-rata $155,5 \mathrm{x} / \mathrm{mnt}$. Hal ini menunjukkan bahwa heart rate neonatus juga di pengaruhi oleh pengalaman ketidaknyamanan yang di dapatkan sebelumnya, di buktikan rata-rata heart rate pada neonatus pengambilan ke 1 lebih rendah di bandingkan pada neonatus pada tindakan ke 2 . Hal ini di dukung oleh Slater dkk bahwa Anatomi dan fisiologi dasar nyeri telah muncul pada neonatus preterm. Mekanisme anatomi, fisiologi dan biokimia terhadap nyeri / ketidaknyamanan telah ada sejak awal kehidupan janin didalam kandungan, oleh karena itu neonatus telah dapat merasakan nyeri seperti anak yang lebih besar. Namun disisi lain mekanisme inhibisi dalam penghantaran nyeri belum sepenuhmya terbentuk sebagaimana halnya dengan jalur ascenden. neonatus yang dirawat di ruang perinatal sering mendapatkan pengalaman ketidaknyamananan untuk periode waktu yang panjang. Neonatus memiliki peningkatan sensasi nyeri dan lebih sensitif terhadap ketidaknyamanan dibandingkan anak-anak dan dewasa., dan rentan terhadap efek nyeri jangka panjang (Slater, dkk, 2006). Zempsky dkk, menyatakan bahwa neonatus yang baru lahir memiliki pengalaman nyeri/ketidaknyamanan yang lebih sedikit oleh karena sistem persarafan belum sempurna, namun penelitian terakhir mendukung hipotesis bahwa masa perinatal akan terjadi peningkatan sensitifitas terhadap nyeri/ketidaknyamanan. Adanya pengalaman terhadap nyeri/ ketidaknyamanan pada masa neonatus dapat meningkatkan risiko efek nyeri bukan hanya dalam jangka pendek seperti iritabilitas, rasa takut terhadap nyeri, gangguan tidur, peningkatan konsumsi oksigen namun juga dalam jangka waktu panjang seperti ingatan terhadap nyeri, retardasi dan perubahan respon terhadap nyeri itu sendiri. Berdasarkan teori di atas pengambilan darah ke 2 memberikan pengaruh respon neonatus terhadap ketidaknyamanan/nyeri yang di alami sehingga memberikan pengaruh terhadap heart rate neonatus. Oleh karena itu peneliti hanya meneliti 17 neonatus yang berhenti menangis setelah diberikan tehnik 4S,s (swaddling, side, shushing, swingging) untuk mengetahui sejauh mana keefektifan tehnik 4S's (swaddling, side, shushing, swingging) terhadap heart rate neonatus paska pemgambilan darah vena.

\section{Heart Rate neonatus Kelompok kontrol}

Berdasarkan karakteristik neonatus kelompok kontrol jenis kelamin neonatus terbanyak adalah laki-laki sebanyak 9 (53\%), jenis persalinan terbanyak SC yaitu 13 (76\%), dan prosedur pengambilan darah yang terbanyak adalah pengambilan darah yang ke 2 yaitu 8 (47\%), usia terbanyak 0-3 hari yaitu $14(82 \%), \mathrm{SaO} 2$ rata-rata $91,3 \%$.

Jumlah sampel kelompok kontrol 17 neonatus yang di uji dari 25 neonatus supaya jumlah neonatus yang di uji sama dengan jumlah kelompok perlakuan sehingga data dapat di uji secara stastistik. Hasil observasi Heart rate kelompok kontrol minimal 132 $\mathrm{x} / \mathrm{mnt}$ maximal $162 \mathrm{x} / \mathrm{mnt}$, rata-rata $144,8 \mathrm{x} / \mathrm{mnt}$ ini menunjukkan hasil yang lebih tinggi dari kelompok perlakuan.

Berdasarkan jurnal penelitian Dera Alfiyanti tahun 2010 yang di aplikasikan pada 2 neonatus dengan penggunaan smart jaket untuk meminimalkan 
efek traumatik pada neonatus menunjukkan bahwa neonatus yang mendapatkan kenyamanan hasil EKG nya bagus dan gelombang QRS kompleks terlihat lebih jelas dan bagus kualitas gambarnya.

Parameter fisiologis yang harus dimonitor selama neonatus menjalani perawatan di unit perawatan intensif antara lain adalah: Suhu tubuh, sebagai indikator keefektifan termoregulasi, Denyut jantung menunjukkan indeks fungsi jantung dan kondisi stress/tidak nyaman pada neonatus, Frekuensi pernafasan, $\mathrm{SaO}_{2}$ untuk mengkaji efisiensi aktivitas sistem pernafasan secara kontinyu, Elektrokardiogram (ECG). Pengukuran vital sign sebagai parameter fisiologis juga memberikan indikasi terhadap kondisi umum neonatus. Peningkatan heart rate merupakan salah satu indikasi adanya ketidaknyamanan yang terjadi pada neonatus.

Kelompok kontrol neonatus hanya di lakukan pembedongan (swaddling) saja, yang dirasa masih kurang efektif untuk memberikan kenyamanan pada neonatus paska pengambilan darah vena. Pada pembedongan (swaddling) hanya melibatkan indra perasa saja sehingga kenyamanan yang di hantarkan ke otak juga minimal yang mengakibatkan perangsangan hormon endorpin dan enkefalin yang di keluarkan tubuh sedikit yang akhirnya kenyamanan neonatus tidak maksimal dan heart rate cenderung naik walaupun masih dalam batas normal, $\mathrm{SaO} 2$ pada kelompok kontrol masih dalam batas normal. Pada kelompok kontrol ada 2 neonatus yang heart rate menunjukkan hasil paling tinggi yakni $162 \mathrm{x} / \mathrm{mnt}$ kedua neonatus tersebut di ambil pada tindakan yang ke 2, ini menunjukan bahwa respon neonatus terhadap nyeri/ketidaknyamanan di pengaruhi oleh pengalaman nyeri yang di alami neonatus.

\section{Perbedaan heart rate neonatus kelompok perlakuan dan kelompok kontrol}

Rata-rata heart rate pada neonatus kelompok perlakuan adalah 131,23 x/mnt dan pada kelompok kontrol $144,8 x / m n t$. Hal ini menunjukkan bahwa heart rate yang dialami oleh kelompok perlakuan lebih rendah dibandingkan dengan pada kelompok kontrol. Range normal heart rate antara 100-180x/ mnt, perubahan heart rate disebabkan faktor sistem syaraf yaitu syaraf simpatis dan syaraf parasimpatis. Pengambilan darah vena akan menimbulkan kerusakan jaringan area punksi vena yang mengakibatkan ketidaknyamanan/kecemasan pada neonatus. Efek dari kecemasan merangsang syaraf simpatis untuk melepaskan norepineprin yang berimbas pada penu- runan permeabilitas kapiler pada SA node sehinga meningkatkan pembentukan potensial aksi, menurunkan perlambatan nodus AV node sehinga meningkatkan kecepatan hantaran impuls, menurunkan permeabilitas ion kalsium pada atrium dan ventrikel sehinga meningkatkan kontraktilitas atrium dan ventrikel. Berdasarkan penelitian menunjukkan dengan memberikan teknik menenangkan neonatus yakni 4S's menunjukkan penurunan heart rate yang signifikan. Karena dengan 4S's respon tubuh akan melepaskan endorphin, enkefalin menuju reseptor diameter besar (A beta) sehinga gerbang tertutup dan impuls di hantar ke korteks serebral sehingga kenyamanan dan ketenangan meningkat akhirnya heart rate menurun/normal. Hasil ini mendukung pendapat Harvey Karp bahwa intervensi 4S's dapat menurunkan skala nyeri/ ketidaknyamanan akibat dari tindakan invasif. Pemberian intervensi 4S's didasarkan pada konsep bahwa 4 bulan setelah kelahiran, neonatus belum siap sepenuhnya berada di luar rahim, neonatus merindukan sensasi yang nyaman seperti di dalam rahim. Di dalam rahim ada simfoni sensasi, gerakan bergoyang yang konstan, bunyi mendesing yang konstan yang merupakan suara aliran darah melalui arteri dan menyentuh konstan terhadap dinding rahim. Melalui intervensi 4S's Karp menstimulasi rekondisi dalam rahim.

Intervensi tindakan dengan $4 \mathrm{~S}$ 's merupakan salah satu dari penatalak sanaan nyeri/ ketidaknyamanan non farmakologik yaitu metode distraksi. Distraksi dapat menurunkan persepsi nyeri dengan menstimulasi sistem kontrol desenden sehingga stimulasi nyeri yang ditransmisikan ke otak lebih sedikit. Efektifitas teknik distraksi tergantung pada kemampuan individu dalam menerima dan membangkitkan stimuli sensoris selain dari rangsang nyeri yang diterima. Penurunan nyeri secara umum dapat optimal dengan melibatkan partisipasi aktif dari individu, keterlibatan modalitas sensoris yang digunakan dan minat individu terhadap stimuli (Smeltzer, 2002). Stimulasi dengan melibatkan beberapa indera seperti penglihatan, pendengaran, sentuhan lebih efektif dalam menurunkan ketidaknyamanan/nyeri dibandingkan dengan hanya melibatkan satu indera saja. Intervensi 4S's yaitu Swaddling, Side, Shushing, Swinging, melibatkan beberapa indera sehingga lebih efektif dalam menurunkan nyeri.

Beberapa riset menunjukkan bahwa kegagalan dalam mengatasi nyeri pada neonatus akan menyebabkan perubahan permanen pada proses di otak dan perilaku maladaptif selanjutnya (Anand, 2000). 
Hasil penelitian menunjukkan kelompok perlakuan hasil heart rate minimal $111 \mathrm{x} / \mathrm{mnt}$ maximal 156x/mnt sedangkan kelompok kontrol hasil heart rate minimal $132 \mathrm{x} / \mathrm{mnt}$ maximal $162 \mathrm{x} / \mathrm{mnt}$ kelompok perlakuan lebih rendah di bandingkan kelompok kontrol karena pada perlakuan melibatkan banyak panca indra yakni indra peraba/sentuhan, pendengaran, penglihatan jauh lebih efektif di bandingkan dengan menggunakan satu indra saja yaitu sentuhan saja pada kelompok kontrol.

Dalam pengambilan sampel darah vena tentunya ketrampilan perawat, lingkungan yang tenang, nyaman, neonatus dalam kondisi kenyang sangat mempengaruhi respon neonatus terhadap ketidaknyamanan saat pengambilan darah

\section{SIMPULAN DAN SARAN}

\section{Simpulan}

Berdasarkan hasil penelitian yang dilakukan di ruang Edelweis RSUD Ngudi Waluyo Wlingi tahun 2014 tentang "Pengaruh 4S's (Swaddling, Side, Shushing, Swinging) terhadap heart rate neonatus paska pengambilan darah vena diperoleh simpulan sebagai berikut : Kelompok perlakuan menunjukkan hasil heart rate minimal 111x/mnt maximal 156x/ mnt, rata-rata $131,23 \mathrm{x} / \mathrm{mnt}$. Kelompok kontrol menunjukkan hasil heart rate minimal 132x/mnt maximal 162x/mnt, rata-rata 144,8x/mnt. Tindakan 4S's (Swaddling, Side, Shushing, Swinging) dapat mempengaruhi heart rate neonatus.

\section{Saran}

Diharapkan materi teknik 4S's (Swaddling, Side, Shushing, Swinging ) ini dapat ditambahkan, khususnya pada mata kuliah sistem reproduksi 2 tentang penatalaksanaan neonatus yang mempengaruhi heart rate neonatus. Diharapkan hasil penelitian ini dapat menjadi bahan pertimbangan dalam membuat SOP (Standart Operational Procedures) dalam menenangkan neonatus dan dapat mensosialisasikan kepada ibu, bahwa tindakan 4S's (Swaddling, Side, Shushing, Swinging) sangat bermanfaat bagi neonatus dan menjelaskan efek negatif dari ketidaknyamanan yang tidak segara ditangani. Diharapkan penelitian ini bisa dilanjutkan dan dikembangkan sehingga nantinya bisa menambah pengetahuan dan meningkatkan kualitas SDM perawat dan disosialisasikan, diterapkan dalam memberikan kenyamanan pada neonatus.

\section{DAFTAR RUJUKAN}

Anand K. 2000. Pain, plasticity, and premature birth: A prescription for permanent suffering? $\mathrm{Na}$ ture Medicine; 6:971-73.

Anand K, and Hickey P. Pain and its effects in the human neonate and fetus. New England Journal of Medicine 1987; 317:1321-29.

Anand K, and Scalzo F. 2000.Can adverse neonatal experiences alter brain development and subsequent behavior? Biology of the Neonate; 77:69-82

Babycentre. 2012. Seven Reasons Baby Cry and how to soothe Them. Dibuka tanggal 14 April 2013. Dari http://www.babycentre.co.uk/a536698/ seven-reasons-babies-cry-and-how-to-soothethem-

Bartocci, M, Bergqvist, LL, Lagercrantz, H, Anand, KJ. 2006. Pain activates cortical areas in the preterm newborn brain; 122:109.

Boyse, Keyla. 2007. Pain and Your Infant: Medical Procedures, Circumcision and Teething. http:/ /www.med.umich.edu/yourchild/topics/ paininf.htm dibuka tanggal 20 Nopember 2013.

Dera Alfiyanti. 2010. Pendekatan baru dalam monitoring bayi baru lahir di Neonatal Intensive Care Unit (NICU) dengan menggunakan wearable sensors: sebuah strategi non-invasif untuk meminimalkan efek traumatik pada bayi.

Gupta, S. 2012. The 5S's: Easing Baby Pain After Vaccine Shots. Dibuka tanggal 14 April 2013. Dari http://thechart.blogs.cnn.com/2012/04/16/the5-ss-easing-baby-pain-after-vaccine-shots/.

Harrington, J.W., Logan,S.,Harwell,C., Gardner, J., Swingle, J., McGuire, E and Santos, R. 2012. Effective Analgesia Using Physical Interventions for Infant Immunizations. American Academy of Pediatrics.http://pediatrics.aappublications.org/ content/early/2012/04/11/peds.2011-1607. abstract

Harvey, K. 2002. Bayi Paling Bahagia Sedunia. Jakarta: Gramedia.

Lissauer, T \& Fanaroff, A.A. 2011. Neonatology at Glance, 2nd Edition.Wiley-Blackwell,USA.

McCarroll, E \& Faris, M. 2014. Crying Babies: Answering the call of infant cries. http:// w w w . ch i l d c a r e quarterly. com / fall10_story2a.html. dibuka tanggal 10 Oktober 2014.

Merkel, S. and others, A. 1997. Behavior pain assessment scale . Pediatric Nurse 23(3), p. 293-297.

Slater, R, Cantarella, A, Gallella, S, et al. 2006. Cortical pain responses in human infants. J Neurosci; 26:3662. Bates, C. 2012. Swaddle, Side, Shush, Swing And Suck: How the '5S's' Really Do Stop Your Newborn From Crying. Dari http:// 
www.dailymail.co.uk/health/article-2130576/ How-5-Ss-stop-newborn-crying.html， Dibuka tanggal 18 April 2013.

Nelson, Behrman, Kliegmana Arvin.1999. Ilmu Kesehatan Anak, Edisi 15, Jakarta: EGC, halaman 1568.
Wong, D.L, Hockenberry M, Wilson,D, Winkelstein, M.L, \& Schwartz, P. 2003. Buku Ajar Keperawatan Pediatrik Wong, Ed 6, Vol I.Alih Bahasa Agus Sutarna. Jakarta: EGC. 